\title{
Wiki: uma experiência pedagógica ${ }^{1}$
}

\author{
Mayra Rodrigues Gomes (USP) ${ }^{2}$ \\ Rosana de Lima Soares (USP) ${ }^{3}$ \\ Andrea Limberto Leite (USP) ${ }^{4}$
}

\section{Resumo}

As novas tecnologias associadas à internet trouxeram uma abertura de possibilidades para as produções artísticas e do mundo empresarial em geral. Neste trabalho, analisamos a adoção da ferramenta wiki em sala de aula tendo em vista tal abertura em relação à produção textual. O wiki nos permite questionar os parâmetros da linearidade do texto ao apresentar uma estrutura ramificada e, ainda, investigar a problemática da autoria, se supomos que uma de suas principais características é a autoria coletiva, princípio que define sua função. Assim, através da inovação apresentada na estrutura de edição textual, propomos uma investigação sobre seus efeitos em sala de aula, concentrandonos especificamente em disciplinas da graduação em jornalismo.

Palavras-chaves: Novas tecnologias; educação; wiki; produção textual; autoria

\begin{abstract}
New technologies related to the internet developement have opened possibilities to artistic and enterprise productions in general. In the present work we analyze the possibility of using the wiki tool in the classroom as an openning to text production. Wiki allows us to discuss the limits of text production when facing its ramified structure. Still, it allows us to investigate the matter of authorship, as we consider collective autorship one of the program's main characteristics and a principle that defines its function. Thus, through inovation in the text edition structure, we propose a research about wiki's effects in the classroom, focusing specifically in journalism graduation disciplines.
\end{abstract}

Keywords: New technologies; education; wiki; text production; authorship 
O presente artigo procura descrever e analisar atividades de ensino e pesquisa desenvolvidas junto a alunos do curso de Jornalismo da Escola de Comunicações e Artes da USP, em nível de graduação. Ministramos nesta Escola um conjunto de disciplinas em quatro módulos sob a rubrica Ciências da Linguagem. Estes perfazem um trajeto por teorias da linguagem, metodologias voltadas ao estudo de produtos midiáticos e técnicas de composição de texto.

Assim, transitamos em campo interdisciplinar, entre teoria e prática, a partir de suportes diversificados. Ambicionávamos, há algum tempo, a incorporação de um meio digital a nossos trabalhos com os alunos, meio que não se restringisse aos softwares processadores de texto, mas que, de algum modo, incorporasse a amplitude de oferta da world wide web.

Em 2005, tomamos conhecimento do software livre wiki. Consiste em um software gerenciador de conteúdos que, na realidade, opera como um site e representa um novo passo na evolução da internet porque com ele os usuários passam a ser, ao mesmo tempo, autores, editores e leitores. Como site, é um instrumental propício à interatividade e a conexões em hiperlink, possibilitando a escrita de hipertextos coletivos e colaborativos.

A partir da primeira experiência, em que contamos com o auxílio de Fábio Sasseron, recém-bacharel em Editoração, e de Andrea Limberto Leite, então mestranda em Ciências da Comunicação, a implantação de site wiki, como estratégia pedagógica, tornou-se algo a mais. Pela riqueza de possibilidades, passou a constituir-se como laboratório e, automaticamente, desenhou-se como projeto de pesquisa ${ }^{5}$.

\section{A ferramenta}

O primeiro editor de texto mais disseminado, mas que não possui as características da edição colaborativa é o processador Word, desenvolvido pela empresa Microsoft. A utilização do Word pode ser considerada concomitante à popularização do uso do computador. Ressaltamos este programa pois ele permite uma funcionalidade que a escrita em papel não permitia: trata-se da troca da ordem dos parágrafos após a escrita e também a mudança de 
palavras ou completo apagamento do registro anterior de texto, entre outras características.

Gostaríamos de associar o raciocínio de que a funcionalidade que comentamos está no caminho do desenvolvimento de uma edição colaborativa. É possível que alguém edite um texto em Word e posteriormente outro alguém (outro autor, no caso, e ao mesmo tempo leitor do texto original) reescreva passagens. No entanto, há duas diferenças cruciais para o tipo de editor de texto com os quais trabalhamos. A primeira delas é a possibilidade do trabalho de autoria ser realizado concomitantemente e referindo-se a um lugar comum (online). A segunda, é o arquivamento em banco de dados de todas as alterações realizadas.

Prossigamos, então, com a descrição dos editores de texto que chamaremos de tipo interativo ou colaborativo. As plataformas ou interfaces de tais programas são inúmeras, assim como suas designações. Temos dentre elas: Co-link (www.co-link.org), MediaWiki (www.mediawiki.org), Writley (www.writely.com), Nuvvo (nuvvo.org), Twiki (www.twiki.org), Writeboard (www.writeboard.com), MyWebDesktop.net (www.mywebdesktop.net), Zimbra (www.zimbra.com), MoonEdit (moonedit.com), Gobby (darcs.0x539.de/trac/obby/cgi-bin/trac.cgi), vyew.com ( SubEthaEdit (www.codingmonkeys.de/subethaedit/), EquiText (equitext.pgie.ufrgs.br), Zoho Virtual Office (www.zoho.com), Softalk (www.softalkltd.com).

O desenvolvimento de plataformas de edição de texto colaborativa cresce na medida da possibilidade de que os programadores reestruturem suas funcionalidades. A maioria destes editores têm o código de programação aberto, disponível para reformulação. É o chamado copyleft (em oposição a copyright, que consistiria em uma reserva de direitos autorais). Assim, bem à maneira da edição de texto, a programação também se torna colaborativa.

A característica comum que destacamos entre eles, e que nos importa no trabalho colaborativo, é a possibilidade de que o texto esteja acessível para seus colaboradores e que as interferências fiquem registradas. Dessa forma, as interfaces desenvolvidas para a atividade são executadas online (necessitando conexão com a internet) e associadas a um banco de dados 
(que podem ser de diferentes formatos, interagindo com o servidor web, como o MySQL).

O acesso ao texto num lugar comum aos usuários, mais o armazenamento de informações, é o que consideramos ser a combinação inovadora desses editores de texto. Assim, temos o acesso remoto possibilitado a todos os participantes do exercício de elaboração de texto, com a possibilidade de recuperar a história de tal documento. O que era um resultado apresentado de maneira fechada, completa, como um texto word, ganha a forma de um processo, com uma certa historicidade que permite investigar os caminhos para a produção do texto final.

O programa MediaWiki, que utilizamos na proposta pedagógica de produção de texto, desenvolveu-se inicialmente para atender ao projeto de uma enciclopédia colaborativa, a Wikipedia (www.wikipedia.org). O programa de base foi disponibilizado com seu código aberto para edição e acessível gratuitamente para ser instalado (www.mediawiki.org). Ele depende de um banco de dados do tipo MySQL e pode ser hospedado tanto num servidor Linux, quanto Windows.

Apresentamos, então, os principais recursos oferecidos pela interface MediaWiki. O site é composto de uma página principal à qual há a possibilidade de retornar-se através do próprio endereço do site ou pelo link no menu lateral esquerdo. A página principal já se configura como um artigo dentro da estrutura do texto wiki. Assim, dispõem-se as funcionalidades de edição de texto e de discussão sobre o texto, bem como um link para a recuperação do histórico de edição do presente artigo.

A discussão é uma página associada ao artigo e que permite a troca de informações e principalmente a tomada de decisões sobre o formato e conteúdo finais do artigo em questão. Cada artigo tem sua respectiva área de discussão, que é acessível e editável por todos os leitores/autores do wiki.

Uma das principais funcionalidades que ressaltamos no wiki é o recurso de edição de texto. A cada artigo pode ser acionado o link de edição, que leva a uma caixa de texto em que se pode alterá-lo. Todas as alterações devem ser salvas para que sejam visualizadas por outros usuários. Ressaltamos a rapidez com que esse trabalho pode ser executado, visto que a partir do momento em 
que se salva a alteração, ela é publicada imediatamente e já pode ser reeditada por um outro leitor/autor.

Dentro das possibilidades de edição de texto que o wiki proporciona, destacamos uma delas em particular, que é a criação de links. Este recurso consiste em um dos fatores inéditos da edição de texto nesta plataforma. É possível estabelecer links com conteúdos dentro do próprio texto wiki, como com sites externos.

Dizemos que isto confere ao texto uma característica aberta e também ramificada. O estabelecimento de links confere duas características a mais na edição de texto em wiki, a parte de ser colaborativa: o esgarçamento da construção linear do texto, com o investimento em sua ramificação e, ainda, a possibilidade de conferir a ela uma extensão ilimitada. A última funcionalidade que gostaríamos de destacar é o sistema de armazenamento das informações (no caso, alterações realizadas por outros usuários), apresentado no mesmo formato de páginas do wiki e não em tabelas de banco de dados.

É possível acompanhar as mudanças realizadas em ordem decrescente de datas, ainda com o registro do usuário que no momento trabalhou como autor. As edições podem ainda ser feitas por usuários não registrados no site (caso em que fica registrado o número de IP do computador utilizado) ou podem ser limitadas a um grupo de pessoas inscritas. Neste caso, para realizar alterações o usuário deve estar não só inscrito, mas dar entrada no site (efetuar login). Na proposta pedagógica em questão estamos utilizando um grupo fechado no wiki para efeitos de avaliação e análise.

Devemos indicar, ainda, que a escolha do Mediawiki nos leva a trabalhar com o texto nas características apontadas: ser colaborativo, com registro de informações, e ramificado pela criação de links. Não é central no programa a formatação e diagramação de texto, desenvolvendo recursos para combinar texto e imagem, bem como a alteração de fontes e o trabalho com manchas gráficas, ainda que existam alguns recursos neste sentido (upload de imagens, justificação de parágrafos, entre outros). 


\section{Resultados parciais de pesquisa: primeiras experiências}

Implantamos no primeiro semestre de $2006^{6}$, na disciplina "Ciências da Linguagem: Estudo das Práticas Midiáticas I", um formato que visa organizar a produção textual no site wiki, facilitando tanto o trabalho dos alunos quanto o trabalho de avaliação do professor. Acreditamos que ele mantém, em meio à fluidez inerente à ferramenta wiki, ritmo e padrão necessários à imersão do aluno e à observação do professor. Eis a articulação implantada:

1) Há, na página principal de cada período (matutino e noturno), 10 temáticas diferentes para 10 grupos de alunos, cada uma delas estabelecendo links para 10 páginas específicas (uma para cada grupo). Embora todos os temas devam estar vinculados aos conteúdos da disciplina oferecida, eles são escolhidos pelos próprios alunos, assim como os títulos, abaixo dos quais devem estar os nomes dos participantes de cada grupo.

2) O primeiro mês do trabalho corresponde ao período de familiarização dos alunos com a ferramenta, concomitantemente ao acompanhamento das aulas teórico/expositivas que prosseguem ao longo dos outros meses do semestre.

3) No segundo mês, programam-se reuniões para discussão de pauta, de forma que os grupos coloquem, ao final do mês, um texto/artigo em que a temática escolhida por cada grupo esteja desenvolvida, ainda que de forma incipiente.

4) O terceiro mês de trabalho é dedicado à realização de pesquisa sobre os assuntos interconectados aos seus temas de modo a compor uma rede de links/referências a outros sites da internet, sempre justificando a conexão. É nossa crença que essa determinação incentiva o potencial investigativo e prepara, pelo tipo de exercício realizado, para procedimentos de pesquisa.

5) O quarto e último mês é dedicado ao trabalho de articulação do texto de um grupo com os dos outros grupos da classe, de forma a estabelecer links entre eles e formar confrontos possíveis, até chegar a uma composição final de texto que será avaliada como trabalho de conclusão do semestre.

$\mathrm{Na}$ tentativa de administrar possíveis confrontos, ficou determinado, nesse primeiro momento, que qualquer interferência de um grupo no texto de outro grupo só seria feita mediante prévia conversação entre os colegas. De 
qualquer modo, se um grupo quiser fazer reparos/notações sobre o trabalho de outros, isto é sempre possível na forma de links a funcionarem como citação.

Acreditamos que este exemplo revela o empenho dos alunos, mas mostra, sobretudo, que eles foram buscar, para além dos conteúdos de sala de aula, extensões das teorias e conceitos perpassados remetendo-os a sites e obras disponíveis na internet. Com isso, não só uma reflexão foi desenvolvida, mas também mais informação foi assimilada na forma de contato com pensadores ligados aos temas explorados.

$\mathrm{Na}$ realidade, os links que os alunos estabeleceram funcionaram como ampliação cultural no sentido de captação de conteúdo, mas também como incentivo à investigação e pesquisa.

A observação sobre os procedimentos textuais levou à aplicação de questionário com o objetivo de mapear a atuação dos alunos e a relação destes com a ferramenta.

1) O texto apresentado nas páginas foi escrito pelo grupo todo?

2) Quais as dificuldades de se trabalhar na composição de um texto colaborativo?

3) Houve desconforto em relação às mudanças realizadas por outros colegas?

4) Quais os papéis dos links nos artigos apresentados nas páginas dos grupos?

5) Após a experiência com o wiki da disciplina algum dos alunos passou a contribuir com outros sites que utilizam o mesmo software?

As repostas apresentadas foram as seguintes:

1) Uma grande parte disse que dividem as tarefas entre os membros do grupo, sendo que alguns ficam responsáveis pela redação do texto enquanto aos outros cabe as tarefas de inserção de links e de revisão do texto. Outros grupos, a minoria, disseram que redigiam o texto em grupo e não tinham divisão de tarefas entre si.

2) A maior preocupação ao se trabalhar num texto colaborativo pareceu ser a manutenção da coerência e da coesão do texto. Além disso, citou-se o problema do conflito raro com relação à inserção ou retirada de conteúdo por parte de um dos membros. Os alunos disseram que, às vezes, não concordavam com essas ações. 
3) Não foi apresentado nenhum desconforto em relação às mudanças feitas pelos membros do grupo, exceto o que já foi citado, relativo principalmente à retirada de conteúdo por um membro do grupo sem aviso prévio aos outros membros.

4) Para todos os grupos, os links possuem diversas funções que são comuns entre eles. Os links internos teriam função explicativa sobre um termo, frase ou sobre um autor citado no texto principal; os links externos proporcionariam um aprofundamento num tema ou uma biografia mais extensa sobre um autor. Além dessas surgiram outras respostas, como a função de afirmação da credibilidade do que foi dito no texto.

Com relação à preocupação causada pelos links no que diz respeito à leitura dos textos, os alunos responderam que mesmo que se perca parte da linearidade, os links são úteis porque servem de guia para alguns leitores que procuram um assunto específico. Outros disseram que esperam que os leitores dos textos mantenham a linearidade inicial do texto, lendo-o até o fim, para depois se dirigirem aos links. Nesse primeiro momento, apenas dois alunos afirmaram que passaram a contribuir com outro site wiki, os dois, no caso, contribuíram com a wikipedia (http://wikipedia.org), revisando dados sobre autores e inserindo novas informações que eles coletaram durante o curso.

A partir de nossas observações sobre os textos produzidos pelos alunos na disciplina acima referida, pudemos constituir uma análise que nos leva a outras tantas notações. A consulta ao histórico de mudanças das páginas dos grupos foi o meio utilizado para o desenvolvimento da análise. Através dele foi possivel fazer uma estimativa de quais alunos intervieram mais vezes nos textos. No entanto, é importante notar também se as intervenções foram feitas em intervalos muito curtos de tempo, o que não pode ser considerado uma verdadeira mudança, mas sim uma medida preventiva contra possíveis "perdas" de texto (salvando freqüentemente), provenientes de problemas com a máquina. Dessa forma, consideramos como mudanças significativas apenas aquelas feitas pela mesma pessoa, desde que tenham sido realizadas em dias diferentes.

Em relação ao critério de participação dos grupos no desenvolvimento do artigo, diversas maneiras de intervir no texto foram encontradas pelos alunos. Na maior parte das vezes, havia uma divisão não bem delimitada das 
tarefas, mas geralmente um ou dois usuários inseriam os textos e o restante do grupo apenas revisava e inseria links. Houve casos em que essa divisão ficou bem clara e casos em que ela nunca existiu. Esta última situação pode ser dividida em dois tipos: a dos grupos em que não houve divisão de tarefas entre os membros, sendo que todos eram responsáveis por todas as questões relativas ao texto; e a dos grupos que realmente redigiram os textos em grupo, ficando todos responsáveis, depois da redação, pela revisão e inserção de links, e também pela finalização dos artigos.

Quanto à qualidade dos textos, a maior parte dos grupos conseguiu resultados satisfatórios, uns realmente bons e outros com qualidade aceitável. Um dos meios encontrados pelos grupos para garantir a unidade textual foi a divisão dos assuntos a serem tratados no artigo em subpartes, cada uma com um subtítulo relacionado a ela. O grupo que mais se destacou nessa tarefa de dividir o texto em subpartes foi o que, além de utilizar esse recurso, criou uma hierarquia dentro do texto utilizando números.

Apesar de a maioria ter conseguido bons resultados na produção colaborativa dos textos, alguns grupos não conseguiram manter a coesão, e até mesmo a coerência, dos mesmos. O caso do grupo em que houve repetição no tratamento de um tema é um bom exemplo de falta de coerência. Em outros casos percebe-se que o texto foi escrito por mais de uma pessoa devido à diferença entre os parágrafos. Estes, às vezes, são muito mais longos do que o restante do texto, ou possuem erros que não foram cometidos por outros usuários. Há também o problema da mistura dos estilos de escrita. Essa foi uma problemática levantada por Jaron Lanier em seu artigo Digital maoism: the hazards of the new online collectivism. Segundo ele, esse é um problema do wiki e dos textos colaborativos em geral publicados na internet.

No que diz respeito à utilização dos links nos artigos, quase todos os grupos utilizaram maciçamente o recurso, com diversas funções. Uma delas era a função de nota explicativa, uma espécie de nota de rodapé utilizada para explorar melhor um termo apresentado no texto, ou apenas para contextualizála caso um leitor nunca tivesse tido contato com o assunto tratado.

Outra função encontrada para o recurso foi a de fornecer a biografia dos autores relacionados no artigo. Este tipo de link também tem, de certa forma, função de nota explicativa, no entanto proporciona ao leitor um 
aprofundamento no assunto, caso the interesse. Esse modelo de link, ao contrário do que foi apresentado anteriormente, é normalmente discutido pelos teóricos da web, pois proporciona ao leitor a possibilidade de formar um texto próprio apenas por seguir o caminho dos links a ele apresentados. Os alunos também fizeram uso de links para reforçar a relação intertextual entre os artigos produzidos pelos outros grupos.

Além das funções apresentadas, outra finalidade encontrada pelos alunos para os links foi a de fornecer citações e obras completas dos autores discutidos no texto. Dessa forma, os leitores têm possibilidade de ter contato não apenas com a história dos autores, mas também com suas obras. Outros links dessa espécie direcionavam os leitores para matérias de jornais que haviam sido citadas no artigo. Esses dois tipos de links permitem que se chegue à informação na fonte da qual ela foi retirada, deixando o leitor livre para fazer sua própria leitura crítica.

\section{Limites entre a produção coletiva e individual em formato wiki}

No segundo semestre de 2006 propusemos uma nova organização dos trabalhos, na disciplina "Ciências da Linguagem: Estudo das Práticas Midiáticas II". Desta vez foram desenvolvidos trabalhos individuais. À rubrica de cada grupo de trabalho formado no semestre anterior estavam acoplados os nomes dos participantes dos grupos. Determinou-se, então, que cada um abrisse, a partir de links com seu nome, uma página de texto na qual produziriam artigo individual a ser avaliado como trabalho final na disciplina, com tamanho mínimo de 3.500 caracteres.

Versando sobre algum tema desenvolvido pela disciplina, sobretudo algum conceito teórico, o artigo deveria, num primeiro momento, constituir-se como texto único. No terceiro mês de trabalho, além das possíveis modificações feitas pelo autor, o artigo deveria estabelecer links com sites da internet, de forma a ampliar/aprofundar conceitos e suas correlações.

Durante o quarto mês - sempre consideradas as possibilidades de reformulações dos textos - os trabalhos individuais deveriam estabelecer, por meio de links, conexão com os trabalhos dos colegas, seja na forma de contraposição, na forma de recurso à expansão de conceito ou na forma de 
demonstração de temática paralela ou conectiva. Ao final desse artigo, foi solicitado a cada aluno que escrevesse um pequeno parágrafo relatando sua experiência com o wiki, suas impressões pessoais, sua avaliação quanto ao potencial da ferramenta e à sua utilização em classe.

Quanto à composição textual, individualmente realizada, notamos alguns avanços que dizem respeito tanto à expansão conceitual quanto à apropriação das possibilidades da ferramenta wiki. Em primeiro lugar, os textos se tornaram mais soltos, criativos e imaginativos, revelando inusitadas conexões que refletiam, evidentemente, gostos e peculiaridades de cada aluno.

Nas páginas produzidas pelos alunos testemunha-se, com clareza, o fato de que os links se propagam, e remetem a locais mais diversificados. Com isso queremos dizer que as referências, além de mencionarem trabalhos clássicos sobre análise narrativa, um dos assuntos da disciplina explorado pelos exemplos que trazemos em anexo, ensaiam outros caminhos e relações, mostrando as ligações dos conceitos teóricos com ocorrências da realidade da vida e, sobretudo, da realidade da vida como mostrada pela imprensa e pela televisão.

Outro fato diferenciador destes trabalhos individuais, se comparados àqueles realizados anteriormente em grupo, foi a importação de imagens. No geral, os alunos procuraram ilustrar seus textos, trazendo figuras do cinema e da televisão, expandindo os recursos visuais da ferramenta wiki. Quando o trabalho com imagens se concretizou a partir da mídia impressa, a fonte de captação foi o próprio jornalismo online.

Cabe perguntar se estes fatos observados, que enriqueceram a produção dos alunos, se devem à maior familiaridade com a ferramenta ou têm sua fonte de impulso no envolvimento que a produção individual supõe. No presente estágio, ainda não podemos fazer alguma afirmativa sobre a gênese dos compromissos, com os trabalhos, demonstrados pelos alunos. É muito provável que a combinatória da familiaridade com a ferramenta tanto quanto o impulso de autoria e responsabilidade pela produção individual tenham igual peso nesta equação.

No entanto, há algo que ainda não mencionamos, embora salte aos olhos, que pode ser imputado à iniciativa individual. Trata-se do fato de que quase todos os trabalhos desta segunda etapa apresentam uma organização 
do tipo capitular, que implica a presença de um sumário. Ou seja, libertos em textos não-interativos, os alunos retornam à ideologia do livro, organizando seus trabalhos em formato tradicional e não a explorando as potencialidades da ferramenta hipertextual como meio de escapar a modelos fixados pela escrita a partir da invenção de Gutemberg.

\section{Wiki e construção de espaços digitais: desdobramentos e possibilidades}

Paralelamente ao desenvolvimento dos sites wiki nas disciplinas de Linguagem I e Linguagem II, um outro grupo de alunos, que já havia passado pela experiência inicial com a ferramenta wiki em 2005, aplicou seus conhecimentos no desenvolvimento de produtos multimidiáticos em formato digital na internet. As atividades foram realizadas nas disciplinas "Ciências da Linguagem: Estudo das Práticas Midiáticas III" e "Ciências da Linguagem: Estudo das Práticas Midiáticas IV", durante o ano de 2006.

$\mathrm{Na}$ primeira delas, os temas teóricos desenvolvidos tratam da conceituação e aplicação de temas relacionados à produção textual e hipertextual, especialmente em textos jornalísticos. Esta é uma primeira distinção em relação às experiências anteriormente relatadas. Ao buscar teorias sobre a definição de texto nos campos da literatura e da comunicação, desenvolvemos com os alunos um percurso que tratou de apontar as transformações nesse conceito até chegar ao seu formato hipertextual, com destaque para os hipertextos digitais. Ao longo do semestre, os alunos do módulo III deveriam realizar, como trabalho final, a criação de produtos hipertextuais não-lineares que pudessem contemplar e ampliar as experiências acumuladas nos módulos anteriores (I e II). O interessante desse trabalho foi notar como pudemos vislumbrar aplicações e desdobramentos do uso da ferramenta wiki em aplicações multimidiáticas disponibilizadas na internet. No módulo IV, tratamos de apresentar aos alunos conceitos mais diretamente relacionados aos discursos jornalísticos em seus vários formatos e apresentações, além de explorar questões relacionadas ao campo da argumentação.

Como parte das atividades do semestre, cada grupo apresentou à classe as etapas percorridas na realização do trabalho e também o produto final, além 
de um relatório de atividades entregue ao professor. O objetivo do trabalho visava o desenvolvimento de um produto hipertextual utilizando uma estrutura narrativa não-linear em mídia digital (poderia haver o uso combinado de formatos, explorando características de cd-roms, blogs, sites, games, além de wikis). Destacamos nesse momento a utilização, por parte dos alunos, de ferramentas digitais para sua comunicação interna e também para a apresentação do projeto inicial e do relatório final, eliminando de maneira mais radical a impressão em papel de textos da disciplina. Além disso, destacamos como ponto fundamental dessa experiência a possibilidade de armazenar e disponibilizar os trabalhos na internet, constituindo um arquivo virtual das atividades realizadas pelos alunos e possibilitando que os textos sejam acessados por outros alunos ou usuários.

As especificidades dos trabalhos produzidos nos módulos III e IV, em que os alunos trabalharam em grupos, encontram-se sobretudo no fato da aplicação do wiki a artigos não-acadêmicos e de formatos variados, que pudessem interessar também a outros públicos na internet. Dessa maneira, atingimos uma outra escala no trabalho, qual seja, expandir o uso da ferramenta para seu caráter público e comunitário, não restrito apenas a um grupo demarcado de usuários. Ao final de cada disciplina, a exemplo dos semestres anteriores, os alunos deveriam escrever um artigo individual em que fossem colocadas suas impressões e avaliação sobre o trabalho desenvolvido.

Como resultado da disciplina "Ciências da Linguagem: Estudo das Práticas Midiáticas III", destacamos os seguintes trabalhos: 1) o site www.bluwiki.org, em que o grupo desenvolveu um espaço conceitual sobre o conceito de hipertexto e avançou as discussões para a reflexão e a produção de um filme em curta-metragem denominado "Perdido no hiperespaço" (roteirizado, produzido e filmado pelo grupo), disponibilizado no YouTube em momento ainda inicial de utilização deste site que hoje se tornou uma imensa videoteca de imagens profissionais ou amadoras, sérias ou lúdicas; 2) a criação do jogo hipertextual Alone with de author, em que o grupo construiu, utilizando um programa para criação de jogos digitais, um espaço interativo em que o usuário encontra diversos filósofos e pensadores, clássicos e contemporâneos, e estabelece um dialogo com seus conceitos e idéias; 3) o site "Biblioteca Personal", uma biblioteca virtual em formato wiki na qual o 
usuário poderia registrar as leituras por ele realizadas estabelecendo ligações entre conceitos e autores; 4) o blog "Magos da linguagem", em que por meio do uso de ferramenta wiki o usuário poderia completar uma narrativa ficcional prédeterminada a partir da atribuição de diferentes finais e combinações de partes a ela; 5) o site "Na teia biográfica", em que o grupo realizou combinando ferramentas de blogs e wikis uma biografia hipertextual não-linear, problematizando assim o conceito de autoria e de identidade a partir de elementos textuais e narrativos; 6) o "Guia Cultural SP", um guia de eventos da cidade de São Paulo em formato wiki, propiciando ao usuário que interagisse com o conteúdo do site e sugerisse programações a partir de sua experiência; 7) o site "Ilha das flores - O retorno', em formato híbrido de blog e wiki para realização de críticas de cinema em formato interativo e hipertextual.

Na disciplina "Ciências da Linguagem: Estudo das Práticas Midiáticas IV", os alunos foram divididos em grupos no início do semestre e deveriam produzir um site completo como trabalho final, cujo tema seria a crítica das mídias. A utilização de recursos interativos era uma das propostas do trabalho - e a combinação de ferramentas diversas, entre elas o wiki - e os resultados superaram, em muito, nossas expectativas. Pudemos contar com a valiosa contribuição da monitora Paula Pereira Paschoalick, mestranda participante do Programa de Aperfeiçoamento de Ensino da USP (PAE), que por possuir conhecimentos avançados de programação e webdesign auxiliou os grupos não apenas na implementação dos sites, mas também em sua criação e desenvolvimento.

Destacamos, desses trabalhos, o elevado grau de reflexão realizado pelos alunos ao longo do processo, que envolveu desde a criação do site até sua implementação e manutenção, e a alta qualidade dos conteúdos produzidos. A proposta do trabalho consistia na construção de um site de caráter jornalístico que realizasse o acompanhamento regular de um produto midiático. Durante os dois primeiros meses, cada grupo deveria apresentar um projeto do site (mapa e conteúdo) e produzir, a cada semana, um texto ou mais textos para o mesmo, acompanhando a produção do veículo escolhido. Os textos poderiam ser coletivos ou individuais, utilizando diferentes recursos: hiperlinks, wiki, blog, fóruns, listas de discussão, entre outros. Poderiam, ainda, possuir diferentes formatos: análises, críticas, matérias, artigos, entrevistas, 
reportagens, sempre sobre um tema presente nas mídias naquele período, mantendo o caráter hipertextual e interativo do site a fim de potencializar os conhecimentos adquiridos com o wiki. Os meses finais do semestre foram dedicados à conclusão de cada site e à criação de conexões entre os mesmos.

Entre os sites desenvolvidos, mencionamos os sites Cultídia, Maça do Pecado, Barraco Virtual e U-Play. Com características distintas - o primeiro, voltado para a produção de uma leitura crítica de editorias de cultura presentes na mídia, o segundo voltado para a análise de programas televisivos populares, o terceiro voltado para a criação multimidiática em espaço digital, e o quarto voltado para a crítica de vídeos diversos veiculados no site YouTube - esses sites podem representar uma síntese consistente do projeto wiki em seus formatos e conteúdos.

Os endereços completos dos sites encontram-se abaixo:

- $\quad$ Cacos da Mídia - http://www42.websamba.com/linguagem/cacos.asp

- $\quad$ Cultídia - http://www42.websamba.com/linguagem/cultidia.asp

- Barraco Virtual - http://www42.websamba.com/videocritica/barraco.asp e http://barracovirtual.multiply.com/

- $\quad$ De olho na Mídia - http://www37.websamba.com/deolhonamidia/

- $\quad$ Olhar do Agora -

http://www40.websamba.com/semestre/olhardoagora.asp

- $\quad$ Cinema Surreal - http://www42.websamba.com/videocritica/surreal.asp

- $\quad$ Maçã do Pecado -

http://www42.websamba.com/videocritica/macadopecado.asp

- $\quad$ Critica $A$ - http://www40.websamba.com/semestre/critica.asp

- U-play - http://www42.websamba.com/videocritica/u-play.asp

- VideoCrítica - http://www42.websamba.com/videocritica/videocritica.asp

- $\quad$ Mídia e Política -

http://www40.websamba.com/semestre/midiaepolitica.asp

- Batalha das Revistas -

http://www40.websamba.com/semestre/batalha.asp

- $\quad$ Outdoor - http://www40.websamba.com/semestre/outdoor.asp

- $\quad$ SobreEntrevistas - http://sobrentrevistas.blogspot.com 
Ao utilizar formas de produção, leitura, divulgação e escrita hipertextual digital, os sites conseguem reunir as características de escrita não-linear e borramento de fronteiras entre autores/leitores de maneira radical. Representam, assim, a concretização dos princípios, conceitos e teorias trabalhados nas disciplinas envolvidas no projeto relatado, estabelecendo para os alunos novas possibilidades de utilização de ferramentas digitais para a produção de hipertextos (acadêmicos ou jornalísticos) e, para as pesquisadoras, novos usos de ferramentas digitais com aplicação pedagógica.

A experiência com a ferramenta Wiki, experiência porque ainda estamos explorando suas possibilidades, terá continuidade nos próximos anos, enquanto aplicação pedagógica. $O$ presente artigo tenta mostrar, em seu trajeto inicial, o trabalho que vem sendo realizado. Acreditamos que ele desenha o potencial da pesquisa e seus benefícios para a área acadêmica em seus dois pólos básicos: professores e alunos, abrindo novos caminhos para a produção (hipertextual) em sala de aula, notadamente em cursos que utilizam o texto como ferramenta básica de trabalho.

Acreditamos, com essa pesquisa, ter ampliado as possibilidades de produção de hipertextos colaborativos em sala de aula, explorando as possibilidades das mídias digitais especialmente no que diz respeito à ampliação da interação autores/leitores. 


\section{Referências bibliográficas}

ARRIADA M., \& RAMOS, E., "Como promover condições favoráveis à aprendizagem cooperativa suportada por computador". In: Revista Iberoamericana de Informática Educacional. Chile: Universidad de Chile, 2000.

BEIGUELMAN, G. Interatividade. Disponível em http://www.itaucultural.org.br/index.cfm?

cd_pagina=2125\&cd_materia=888 e acessado em 30 de agosto de 2004 .

BERGIN, J. "Teaching on the Wiki Web". In: ACM SIGCSE Bulletin. 2002, 34(3)

BOLTER, J. D. The computer hypertext, and the History of Writing. Hillsdale, NJ, EUA: Lawrence Erlbaum Associates, 1991.

CHARTIER, R. A aventura do livro: do leitor ao navegador. São Paulo: Unesp/Imprensa Oficial do Estado de São Paulo, 1998.

CHILLINGWORTH, M. "Wikipedia courts public input". In: Information World Review, 2005, 210, pp.24.

CORRÊA, M. L. G. "Produção textual em cursos de comunicação social: dialogia e veridicção". In: Fragmentos: Revista de Língua e Literatura Estrangeiras. Florianópolis, 2001.

EBERSBACH, A. \& GLASER, M. "Towards emancipatory use of a medium: The Wiki". In: International Journal of Information Ethics, 2004, 11 [10].

FRUMKIN, J. "The Wiki and the digital library". In: OCLC Systems and Services, 2005, 21(1), pp.18-22.

GODWIN-JONES, R. "Emerging technologies: blogs and wikis: environments for on-line collaboration". Language, Learning \& Technology (Refereed). May 1, 2003. University of Hawaii, National Foreign Language Resource Center. Vol. 7. no. 2. p. 12.

REAGLE JR., J. M. Do as I do: leadership in the Wikipedia. Disponível em http://reagle.org/joseph/2005/ethno/leadership.html e acessado em 08/02/2006.

LANIER, J. Digital maoism: the hazards of the new online collectivism. Disponível em http://www.edge.org/3rd_culture/lanier06/lanier06_index.html.

LEÃO, L. (org.). Cibercultura 2.0.São Paulo: Nojosa Edições, 2003.

LEVY, P. A ideografia dinâmica: rumo a uma imaginação artificial? São Paulo: Loyola, 2004. 
MILLARD, E. "Fast Forward - new technologies, such as wikis, blogs and podcasting help media centers create cutting edge e-learning strategies". District Administration (Magazine/Journal). January 1, 2006. Professional Media Group LLC. Vol. 42, $\mathrm{n}^{\circ}$. 1, p.50.

MURRAY, J. H. Hamlet on the holodeck. The future of narrative in cyberspace. $3^{\text {rd }}$ ed. Cambridge, MA: MIT Press, 2000.

NILES, R. "Wikis will help readers direct the community's most powerful voice: opinion writers from younger generation offer fresh perspective". The Masthead (Magazine/Journal). September 22, 2005. vol. 57. no. 3. p. 10 (2)

PARENTE, A. (org.). Imagem-máquina. Rio de Janeiro: 34, 1993.

SASSERON, F. Metawiki. Trabalho de Conclusão de Curso. Departamento de Jornalismo e Editoração, ECA/USP, 2005.

SAUTCHUK, I. A produção dialógica do texto escrito: um modelo de textualização. São Paulo, 2000.

SKIBA, D. "Do your students wiki?". Nursing Education Perspectives (Refereed). March 1, 2005. National League for Nursing, Inc. vol. 26, $\mathrm{n}^{\circ} .2$, p.120 (2).

TURKLE, S. Life on the screen. Identity in the age of the internet. New York: Simon \& Schuster, 1995.

WERTHEIM, M. Uma história do espaço de Dante à internet. Rio de Janeiro: Jorge Zahar Editor, 2001.

\footnotetext{
${ }^{1}$ Mesa apresentada no Multicom - II Colóquios Multitemáticos em Comunicação.

${ }^{2}$ Mayra Rodrigues Gomes. Professora Doutora, Livre Docente, do Departamento de Jornalismo e Editoração da Escola de Comunicações e Artes da Universidade de São Paulo, Pesquisadora Principal, junto ao Projeto Temático, apoio FAPESP, do Eixo O Poder e a Fala na Cena Paulista. Líder do Projeto Labirintos Textuais - investigação dos caminhos para a incorporação da ferramenta wiki em sala de aula, com apoio do CNPq. Autora, dentre outras obras, do livro Poder no Jornalismo. E-mail: mayra@sdev.com.

${ }^{3}$ Rosana de Lima Soares é doutora em Ciências da Comunicação pela Escola de Comunicações e Artes da USP, professora e pesquisadora do curso de Graduação em Jornalismo e do Programa de Pós-Graduação em Ciências da Comunicação desta mesma Escola. É autora de Imagens veladas. Aids, imprensa e linguagem (São Paulo, Annablume, 2001) e de diversos artigos científicos. E-mail: rolima@usp.br.

${ }^{4}$ Andrea Limberto Leite é doutoranda do programa de Ciências da Comunicação da Escola de Comunicações e Artes da USP. Concluiu mestrado na mesma instituição com o trabalho $O$ traçado da luz - um estudo da sintaxe televisiva em reportagens telejornalísticas. E-mail: andrealimberto@gmail.com.

${ }^{5}$ Projeto "A ferramenta wiki: uma experiência pedagógica", apoiado pelo CNPq, por meio de recursos para compra de equipamentos e material de apoio, e pela Fapesp, por meio de bolsa de iniciação científica para a aluna Mayara Barilli Enohata.

${ }^{6}$ As disciplinas "Ciências da Linguagem: Estudo das Práticas Midiáticas I" e "Ciências da Linguagem: Estudo das Práticas Midiáticas II” utilizaram os sites www.eca.usp.br/gdmat06 e www.eca.usp.br/gdnot06
} 